with his 'healthy' plants. Since it is probable that Scott's healthy plants were also X-infected (see our analysis of Stock Seed tubers), what he was actually doing was correlating reduction in yield with severity of symptoms. The question that really needs answering is: Does the presence of virus $\mathrm{X}$ in a given potato variety materially reduce the yield when there is little or no visible adverse effect upon the plant itself ? There seems little doubt that there is a considerable reduction in yield. Bald ${ }^{4}$ in Australia has published some results of experiments on these lines. He made yield trials on Up-to-Date potatoes, grading the severity of strains of X present in twenty-five families on the basis of their symptoms on an indicator plant (Datura). Bald estimated that the yield from completely healthy plants should be some 12 per cent higher than that from plants infected with the mildest strains of virus $\mathrm{X}$.

Taking advantage of the opportunity offered by the 1,500 tubers from Ireland previously mentioned, all of which had been tested and found to be virus-free, a comparatively extensive yield trial was carried out at Cambridge. The potatoes used consisted of one early variety, one second early, three early main crops and four late main crops.

The potatoes were planted in sixty plots, each of four rows of ten half-tubers, and the middle two rows only of each plot were weighed on sampling. As soon as the plants were six inches above ground, half the plants were inoculated with a very mild strain of $\mathrm{X}$ derived from some Stock Seed Arran Peak potatoes. This strain of virus was deliberately chosen for its mildness and was by no means the most severe of those isolated from tubers having a Stock Seed certificate.

Some weeks later, twenty-five of the inoculated plants were selected at random and tested for the presence of virus, and all gave a positive reaction for virus $X$. It thus seems fair to assume that the inoculations had been effective, although it was not possible during the summer to pick out the inoculated plents by inspection.

On harvesting and weighing the tubers, it was found that the yield from the inoculated plants was 12 per cent below that of the virus-free plants, a difference which is highly significant. All the varieties showed reduction in yield from infection by virus $\mathrm{X}$, but the data are not sufficient to differentiate varietal reaction with certainty. During the season, 105 of the healthy plants which were afterwards harvested were tested and found to be still virus-free.

These results seem to prove that infection with virus $\mathrm{X}$, even with those strains which are normally passed over by the Scotch potato inspectors, results in a considerable loss of erop.

What evidence we have suggests that the elimination of potato virus $\mathrm{X}$ from the Scotch seed potatoes is by no means impossible. Since it appears that the spread of virus $X$ in the field is slow and there is little evidence of its infiltration into a crop completely free from the start, the solution apparently lies in a gradual replacement of the X-infected Stock Seed, and in this process we hope that the stocks built up by the Plant Virus Research Station in conjunction with the National Institute of Agricultural Botany may play their part.

\footnotetext{
${ }^{1}$ Loughnane, J. B., and Murphy, P. A., Sci. Proc. Roy. Dublin Soc., 28, 1 (1938).

'Clinch, P., Loughnane, J. B., and Murphy, P. A., Sci. Proc. Roy. Dublin'Soc., 22, 17 '(1938).

scott, R. J., Scott. J. Agric., 23, No. 3 (1941).

- Bald, J. G., Aust. Coun. Sci. Indust. Res. Bull. 165 (1943).
}

\section{SOIL CONSERVATION IN THE BRITISH COLONIAL EMPIRE}

$\mathrm{A}$

RECENTLY published article; "Soil Erosion and Soil Conservation in the Colonial Empire", by H. A. Tempany, G. M. Roddan and L. Lord (Emp. J. Exp. Agric., 12, 121; 1944), brings the story of soil conservation in the British Colonies up to date. Much of the story is by now well known, and should be still better known, for it concerns closely the future welfare and sometimes the very existence of British Colonial territories. The menace of soil erosion has perhaps been somewhat exag. gerated in the past; if so, it has been done with good reason, for the action necessary to remove the menace has only been taken after the people and more particularly the government authorities in London and the Colonies were thoroughly aroused by fear of catastrophe. Soil erosion is still prevalent and increasing throughout Africa, Ceylon, the West Indies and the Mediterranean Dependencies, but the fear of it seems to be abating. It has been shown that erosion can be controlled by apparently simple measures. As yet there are few areas where it has been completely controlled, but the knowledge that it can be has engendered confidence that it will be, and there is a tendency now to play down the menace, which in fact is neither greater nor less than it was.

The War has had a certain, not entirely unfavourable, influence on the progress of soil conservation. It has seriously depleted staffs and held up the construction of anti-erosion works which are often urgently needed; but at the same time it has helped to eliminate one of the root causes of soil depletion and erosion, namely, agriculture for export in a world market. The immediate effects of the War on soilconservation programmes have undoubtedly been serious, but the long-term effects in promoting a change in methods of land utilization may be beneficial.

Many Colonial administrations now take a direct part in soil conservation, either through governmentoperated soil-conservation boards or committees, or by propaganda, education and the granting of subsidies for anti-erosion work. An important function of government is to promote co-operation between different departments (for example, of agriculture, forestry, public works, etc.), for soil conservation is the concern of the whole community. The authors give several instances where such co-operation is being realized with great advantage to the land. An important recent factor has been the provision of money from the Imperial Treasury through the Colonial Development and Welfare Fund for soilconservation works.

Short accounts are given of the state of erosion and of the counter-measures being taken in each of the Colonial dependencies. The first impression given is that soil conservation is much the same everywhere. The following quotation refers to Basutoland, but the words are repeated with little variation in describing conservation measures in most of the other Colonies.

"The measures adopted comprised the laying out of contoured, broad-based terraces and the introduction of ploughing along the contour, the construction of earth-dams to check gully erosion and provide additional water-supplies for stock, combined with the planting of grass and trees to stabilize 
contour banks and to assist the silting up of gullies, and the fencing of the banks of dams and of plantations to prevent damage by live stock. . . .

"Combined with these measures there must be improved methods of agriculture based on the introduction of mixed farming in place of the existing system. It is considered that the maintenance of crumb structure in the soil should be the aim and that this can only be maintained by suitable agricultural methods".

Many of the Colonies are still at the early contouring stage of soil conservation, at which the most urgent need is to construct mechanical barriers to run-off water and eroding soil. Some have reached the 'strip-cropping' stage, where contour cultivation is combined with an appropriate variant of ley farming, with the purpose of maintaining a crumb structure which will enable the soil to resist erosion with less absolute reliance on engineering constructions. Particular note may be taken of the remarkable success in restoring soil condition and fertility on exhausted land, achieved in Uganda by stripcropping with elephant grass. Simultaneously, and not only in Uganda, local inhabitants are increasingly appreciating the value of livestock as an integral part of farming and not merely as a symbol of wealth.

Throughout the British Colonial Empire, agriculture is evolving at an accelerating pace from primitive, shifting cultivation to settled, intensive systems. There is danger now, as there has been always, that evolution may get out of hand ; but at least we know what the goal is, we can even define it in terms of the physical properties of a fertile, erosion-resistant soil, and we know what agricultural operations will or will not advance the goal. The task of the future will be to synthesize the separate favourable operations into workable systems of land use. The engineering problems of soil conservation have been solved; the agricultural problems are well on the way to solution; and last, but by no means least, the complex social problems still remain to be solved.

\section{OBITUARIES}

\section{Sir Charles Vernon Boys. F.R.S.}

Charles Vernon Boys was born at Wing in the county of Rutland on March 15, 1855, the son of the Rev. Charles Boys. Wing continued to be his home for many years, and it was in his father's garden there that Boys thirty-three years later made with his radio-micrometer his well-known experiments on the heat received from the moon and stars.

At the beginning of his delightful little book on "Soap Bubbles and the Forces which Mould Them", Boys tells how his interest in science was first awakened. "To G. F. Rodwell, the furst Science master appointed at Marlborough College, this book is dedicated by the author as a token of esteem and gratitude, and in the hope that it may excite in a few young people some small fraction of the interest and enthusiasm which his advent and his lectures awakened in the author, upon whom the light of Science then shone for the first time."

From 1873 until 1876, Boys was a student at the Royal School of Mines. In his Guthrie Lecture, delivered before the Physical Society of London in 1934, he mentioned that he was for a short time at a colliery, and that he was brought back to South Kensington by Guthrie, who made him his private assistant and gave him a life membership of the Physical Society. His connexion with that Society always remained a close one; he succeeded Guthrie as its demonstrator in 1886 and continued to be its demonstrator and librarian until 1898; he was later to become its president and was its second Duddell medallist. It was to the Physical Society that much of his work was communicated, including his first paper on "A Condenser of Variable Capacity and a Total Reflection Experiment". This was published in 1879, and in the title Boys is described as "Lecturer for the term on Natural Science at Upping. ham School". In this and the following year papers were published by Boys and Guthrie on "Magnetoelectric Induction" and by Boys himself "On an Integrating Machine". The latter was the first of many papers dealing with practical mathematics, including one on "An Elliptograph" published in his eighty-ninth year.

Boys was demonstrator of physics at the Royal College of Science, South Kensington, from 1881 until 1889, when heं became assistant professor. Much of the work for which Boys is best known was carried out or begun during the years 1887-90. A preliminary note on the radio-micrometer was communicated to the Royal Society on February 24, 1887. In the tests of the method there described, he had used spun glass for the suspension of his radiomicrometer. In a note added a month later, he states that he has since found a method of producing fibres immensely superior to those of spun glass. These fibres of fused quartz obtained by his bow-andarrow method were described in a paper, read before the Physical Society a little later in the same year, on the production, properties and some uses of the finest threads. The many uses of threads of fused quartz made possible by their perfect elasticity and great strength are there pointed out. An account of the perfected radio-micrometer was given to the Royal Society in the following year. He found a suitable application for the instrument in an investigation "On the Heat of the Moon and Stars", begun in September 1888 and published in the Proceedings of the Royal Society two years later. Boys found the radio-micrometer amply sensitive for the comparison of the heat received from different small areas of the moon's surface ; it gave no certain indication of any heat received from even the brightest stars, although able to detect the heat received from a candle flame more than a mile away.

In 1889, Boys communicated to the Royal Society his ideas on improvements in the Cavendish experiment to determine the constant of gravitation, pointing out the advantages of reducing the scale of the apparatus; the use of a fibre of fused quartz for the suspension made it practicable to carry this reduction very much further than would otherwise have been possible. Boys' final measurements of the Newtonian constant of gravitation were carried out in the Clarendon Laboratory, Oxford, and published by the Royal Society in 1894. He had succeeded in reducing the length of the torsion rod from which the attracted masses were suspended from the six feet of the original Cavendish experiment to less than one inch ; the measurement was more accurate than any previously made of the constant of gravitation.

From indications which he had observed of the high electrical insulating power of quartz fibres, Boys was led to make investigations on quartz as an insulator, which were published in 1890. Besides proving the great merits of quartz as an insulator, 